\title{
Curcumin inhibits proliferation of gastric cancer cells by impairing ATP-sensitive potassium channel opening
}

Xiaohong Liu ${ }^{1 \dagger}$, Kai Sun ${ }^{2+}$, Hao Chen ${ }^{1}$, Ailin Song ${ }^{1}$, Xiaoyun Zhang ${ }^{3}$, Xu Zhang ${ }^{3^{*}}$ and Xiaodong He $\mathrm{H}^{4^{*}}$

\begin{abstract}
Background: This study was aimed to investigate whether ATP-sensitive potassium channel $\left(K_{\text {ATP }}\right)$ is involved in curcumin's anti-proliferative effects against gastric cancer.

Methods: In an in vitro study, gastric cancer cell line SGC-7901 was treated with curcumin at serial concentrations and co-administrated with the $\mathrm{K}_{\text {ATP }}$ opener, diazoxide. The effect of curcumin and diazoxide on proliferation were assessed by MTT assay. Mitochondrial membrane potential (MMP) was studied by flow cytometry detection of rhodamine 123 staining. Apoptosis was evaluated by flow cytometry detection of Annexin $V$ propidium iodide double staining. In an in vivo study, SGC-7901 cells were planted into nude mice as xenografts. Animals were treated with curcumin co-administered with diazoxide. Tumor volume and tumor weight were observed.

Results: Curcumin incubation significantly induced loss of MMP in SGC-7901 cells in a dose- dependent manner $(P<0.05)$; the cell apoptotic rate also dramatically increased after curcumin incubation in a dose-dependent manner $(P<0.05)$. After co-administration with diazoxide, however, we found that both the MMP-loss-inducing and the apoptosis-inducing effects of curcumin in SGC-7901 cells were significantly impaired (all $P<0.05$ ). As a result, the proliferation of SGC-7901 cells was maintained by diazoxide treatment.
\end{abstract}

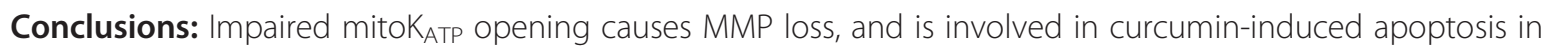
gastric cancer.

Keywords: apoptosis, curcumin, gastric cancer, KATP

\section{Background}

As the third leading cause of death in men and fourth in women with malignant tumors, gastric cancer is now threatening people's lives worldwide [1]. Gastric cancer is one of the highly malignant carcinomas arising from epithelial cells, and is characterized by therapeutic inefficiency and poor prognosis [2]. Like most malignant tumors, the malignancy of gastric cancer is caused by uncontrolled cell proliferation, invasion, and metastasis. The therapeutic options for gastric cancer are often limited because most patients with gastric cancer are

\footnotetext{
*Correspondence: Zhangxu64@163.com; hxd@|zu.edu.cn

${ }^{\dagger}$ Equal contributors

${ }^{3}$ Department of Pathology, Lanzhou University Medical School, 199 West Donggang Road, Lanzhou, Gansu 730000, China

${ }^{4}$ Lanzhou University, 199 West Donggang Road, Lanzhou, Gansu 730000, China

Full list of author information is available at the end of the article
}

diagnosed at an advanced stage [3]. Currently, chemotherapy and radiotherapy are employed to treat gastric cancer at an advanced stage. However, the side effects of these therapies restrict their application and lower the quality of life of patients [4]. Traditional Chinese medicine has been effectively applied in treating malignant diseases for a long time in Eastern Asia [5]. Several monomers, including curcumin, discovered from traditional Chinese medicine formulas have been shown to have anti-cancer activities in previous studies [6]. However, the molecular mechanisms for these activities are still unclear.

Natural extracts or products have attracted attention and become the focus of anti-cancer drug research because over two-thirds of novel anti-cancer drugs discovered in recent decades are of natural original [7]. Curcumin, also known as diferuloylmethane, is extracted from the rhizome 
of Curcuma longa. The spectrum of biological activities of curcumin is thought to be wide, including anti-angiogenic, anti-oxidant, anti-inflammatory and anti-diabetic effects [8]. Previous studies have shown that the expression of oncogenes [9], transcription factors [10], cytokines, and growth factors [11] was modulated in the anti-cancer effects of curcumin. Although several mechanisms regulating proliferation and apoptosis of curcumin have been investigated, many more studies are still needed.

ATP-sensitive potassium channels, also referred to as $\mathrm{K}_{\mathrm{ATB}}$ are distributed throughout the organs and tissues, including skeletal muscle, cardiac muscle, brain, and kidney [12]. $\mathrm{K}_{\mathrm{ATP}}$ is characterized by a hetero-octameric molecular structure; it is composed of four Kir6 and four sulphonylurea receptor subunits [13]. It is now believed that the fundamental function of $\mathrm{K}_{\text {ATP }}$ is to adjust membrane excitability to cellular metabolic status [14]. $\mathrm{K}_{\text {ATP }}$ located on the mitochondrial membrane is called mito$\mathrm{K}_{\mathrm{ATB}}$ the opening of which reduces the mitochondrial transition opening permeability by increasing the activity of inwardly rectifying potassium channels under stressful conditions $[15,16]$. Thus, opening of the mitoK $\mathrm{ATP}_{\mathrm{AT}}$ could attenuate cell apoptosis by maintaining mitochondrial membrane potential (MMP) [17].

A recent study preliminarily established the relationship between mitoK $\mathrm{ATP}_{\mathrm{AP}}$ and the proliferation of malignant cancer cells, such as glioma cells [18]. This association aroused our interests in exploring whether the possibility that curcumin's anti-cancer effect on gastric cancer is related to mitoK $\mathrm{ATP}_{\mathrm{AT}}$. In this study, we investigated the effect of curcumin and the selective mitoKATP opener diazoxide on proliferation, mitochondrial transition opening permeability, and apoptosis in human gastric cancer cells SGC7901 in vitro. A corresponding in vivo study was also implemented. Our results will contribute to a deepened understanding of the molecular mechanisms of curcumin's anti-cancer activity.

\section{Methods}

\section{Cell culture and treatment}

Human gastric cancer cell line SGC-7901 was purchased from the American Type Culture Collection and cultured in DMEM (Gibco) supplemented with 10\% FBS (Gibco). The cells were maintained in a humidified cell incubator (Thermo Scientific, Pittsburgh, PA, USA) containing $5 \% \mathrm{CO}_{2}$ at $37^{\circ} \mathrm{C}$. Equal numbers of cells were divided into seven independent groups: a control group (C), a low-dose curcumin group (LCur), a medium-dose curcumin group (MCur), a high-dose curcumin group (HCur), a low-dose curcumin group treated with diazoxide (LCur + DZ), a medium-dose curcumin group treated with diazoxide (MCur $+\mathrm{DZ}$ ) and a high-dose curcumin group treated with diazoxide (HCur + DZ).
In the control group, cells were maintained in culture medium, as described; in LCur, cells were treated with curcumin (Sigma-Aldrich, St. Louis, MO, USA) solution at concentration of $15 \mu \mathrm{mol} / \mathrm{l}$; in MCur, cells were treated with curcumin solution at a concentration of $30 \mu \mathrm{mol} / \mathrm{l}$; in HCur, cells were treated with curcumin at a concentration of $60 \mu \mathrm{mol} / \mathrm{l}$; in LCur $+\mathrm{DZ}$, cells were treated with diazoxide (Sigma-Aldrich) at a concentration of $100 \mu \mathrm{mol} / \mathrm{l}$ together with curcumin at a concentration of $15 \mu \mathrm{mol} / \mathrm{l}$; in MCur $+\mathrm{DZ}$, cells were treated with diazoxide at a concentration of $100 \mu \mathrm{mol} / \mathrm{l}$ together with curcumin at a concentration of $30 \mu \mathrm{mol} / \mathrm{l}$; in HCur $+\mathrm{DZ}$, cells were treated with diazoxide at concentration of $100 \mu \mathrm{mol} / \mathrm{l}$ together with curcumin at a concentration of $60 \mu \mathrm{mol} / \mathrm{l}$.

\section{Cell proliferation assessment}

A 3-(4,5-dimethylthiazol-2-yl)-2-5-diphenyltetrazoliumbromide (MTT) assay was employed to assess the proliferation of SGC-7901 cells. Briefly, $1 \times 10^{4}$ cells per well were planted in a 96-well culturing plate (Corning Costar, Corning, NY, USA) for 24 hours and then treated with diazoxide and curcumin, as described. Then $20 \mu \mathrm{l}$ MTT (Sigma-Aldrich, $5 \mathrm{mg} / \mathrm{ml}$, dissolved in PBS) was added to each well and $150 \mu$ dimethylsulfoxide (SigmaAldrich) was added to replace medium from each well. Absorbance at $450 \mathrm{~nm}\left(A_{450}\right)$ was measured using a plate reader (Bio-Rad, Hercules, CA, USA). The growth inhibition rate was calculated using the formula:

$$
\begin{aligned}
\text { Inhibition rate }= & {\left[1-\left(A_{450} \text { treatment } / A_{450} \text { control }\right)\right] } \\
& \times 100 \%
\end{aligned}
$$

\section{Cell apoptosis assay}

The apoptosis assessment of SGC-7901 cells in each group was carried out by flow cytometry using an Annexin V-FITC Apoptosis Detection Kit (BD, San Jose, CA, USA) as described previously [19]. Briefly, equal numbers of cells from each group were washed by PBS and titrated by binding buffer to concentrations of $1 \times$ $10^{6} \mathrm{cell} / \mathrm{ml}$. Then $100 \mu \mathrm{l}$ of this cell suspension, $5 \mu \mathrm{l}$ Annexin V-FITC solution and $5 \mu \mathrm{l}$ propidium iodide were added to a culture tube for $15 \mathrm{~min}$ incubation in a dark chamber. After $400 \mu \mathrm{l}$ binding buffer was added to each tube, apoptosis was then analyzed by a fluorescenceactivated cell sorting flow cytometer (BD, San Jose, CA, USA).

\section{Mitochondrial membrane potential (MMP) detection}

The MMP in SGC-7901 cells was determined by detection of rhodamine 123 staining by flow cytometry following the protocols described in a previous study [19]. Cells from each group were washed by PBS twice then 
titrated to $1 \times 10^{6}$ cells $/ \mathrm{ml}$. Rhodamine 123 solution (Beyotime, Shanghai, China) was then added to the cell suspension at a final concentration of $1 \mu \mathrm{mol} / \mathrm{l}$. After incubation at $37^{\circ} \mathrm{C}$ in a dark chamber for $30 \mathrm{~min}$, the fluorescent signal of rhodamine 123 released from cells was analyzed by a fluorescence-activated cell sorting flow cytometer (BD, San Jose, CA, USA) at $529 \mathrm{~nm}$.

\section{In vivo xenograft tumor study}

Cultured SGC-7901 cells were suspended and titrated in PBS at a concentration of $1 \times 10^{7} / \mathrm{ml} .100 \mu \mathrm{l}$ of the cell suspension was subcutaneously injected into the right armpits of male BALB/C nude mice (Animal Experimental Center of the Fourth Military Medical University) with a mean body weight of $(17.64 \pm 5.19) \mathrm{g}$. After the volumes of the xenograft tumors exceeded $100 \mathrm{~mm}^{3}, 18$ mice were divided into three independent groups randomly and evenly (six mice per group); namely, a control group (C), a curcumin treatment group (Cur) and curcumin and diazoxide co-treatment group (Cur $+\mathrm{DZ})$. In Cur + DZ, mice received peritumoral injections of curcumin $(50 \mathrm{mg} / \mathrm{kg})$ applied together with peritumoral injections of diazoxide $(10 \mathrm{mg} / \mathrm{kg})$ twice per day for 2 weeks. In Cur, mice received peritumoral injections of curcumin $(50 \mathrm{mg} / \mathrm{kg}$ ) twice per day for 2 weeks. In $\mathrm{C}$, mice received peritumoral injections of physiological saline twice per day for 2 weeks. The animal treatment protocols were in accordance with our pre-experimental results (not shown) and several previous studies [20,21]. The volume of tumor was measured twice per week and calculated by the formula:

$$
\text { Volume }=\text { Length } \times \mathrm{Width}^{2} \times 1 / 2
$$

The tumor was also weighted after the mice were sacrificed. All animal experimental procedures were performed in accordance with the National Institutes of Health Guide for the Care and Use of Laboratory Animals.

\section{Statistical considerations}

All data collected in this study are expressed as mean \pm standard deviation. The statistical analysis was processed by software SPSS (version 16.0) by analysis of variance (ANOVA), least-significant difference and Fisher exact tests. $P<0.05$ was considered statistically significant when comparing differences.

\section{Results}

Curcumin inhibited proliferation of SGC-7901 cells but this was alleviated by diazoxide co-administration

As shown in Figure 1, according to the results of the MTT assay, curcumin elevated inhibition rate in a concentration-dependent manner in LCur $(9.5 \% \pm$ 2.10\%), MCur $(23.2 \% \pm 7.21 \%)$, and HCur $(39.4 \% \pm$

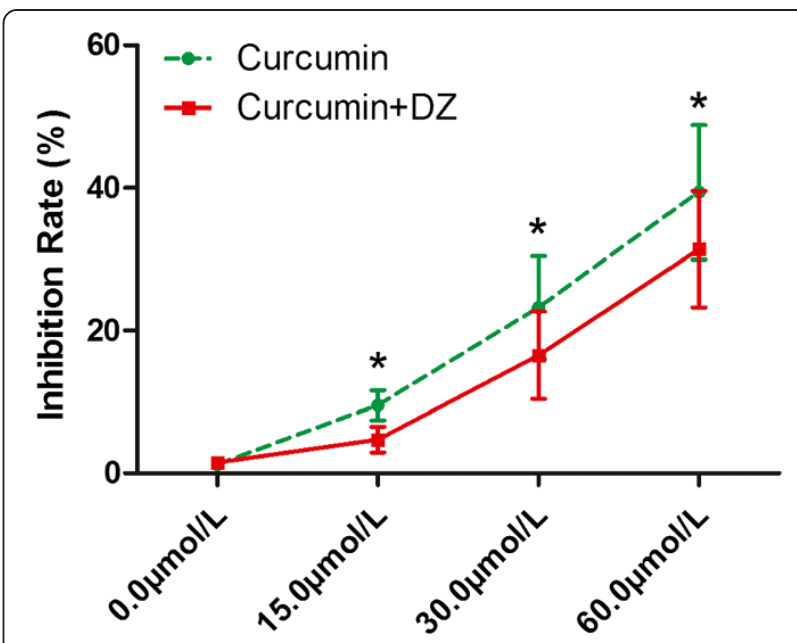

Figure 1 Effects of curcumin and its co-administration with diazoxide on proliferation of SGC-7901 cells. Cell proliferation was assessed by MTT assay. Graphs shows inhibition rate of SGC-7901 cells treated by curcumin (red) and co-administration of curcumin and diazoxide (green). Values are represented as mean \pm standard deviation. ${ }^{*}$, values are significantly different when compared with control; \#, values are significantly different when compared with curcumin treatment.

9.43\%) compared with $C(1.20 \% \pm 0.25)$ (all $P<0.05)$. However, after co-administration of diazoxide, the inhibition rate was decreased in LCur + DZ $(6.72 \% \pm 1.80 \%)$, MCur + DZ (16.55\% $\pm 6.11 \%)$, and HCur + DZ (31.43 \pm $8.15 \%)$ compared with corresponding LCur, MCur, and HCur (all $P<0.05)$.

\section{Co-administration of diazoxide impaired curcumin's effects of decreasing mitochondrial membrane potential (MMP) in SGC-7901 cells}

In a concentration-dependent manner (Figure 2), curcumin lowered MMP in SGC-7901 cells in LCur $(77.51 \% \pm$ 8.13\%), MCur $(62.07 \% \pm 4.52 \%)$, and HCur $(59.18 \% \pm$ $9.30 \%)$ compared with $\mathrm{C}(95.40 \% \pm 7.62 \%)$ (all $P<0.05)$. However, MMP was significantly higher with the coadministration of diazoxide; LCur + DZ (87.33\% $\pm 4.68 \%)$, MCur + DZ (59.18\% $\pm 5.92 \%)$, and HCur + DZ (65.29\% \pm 6.10\%) (all $P<0.05)$.

\section{Co-administration of diazoxide mitigated apoptosis in curcumin-incubated SGC-7901 cells}

Detected by flow cytometry, compared with C $(2.44 \% \pm$ $0.79 \%)$ the apoptosis rate of SGC-7901 cells was increased by curcumin incubation in a concentrationdependent manner in LCur $(18.94 \% \pm 2.32 \%)$, MCur $(35.21 \% \pm 2.77 \%)$, and HCur $(63.09 \% \pm 3.05 \%)$ (all $P<$ $0.05)$. When applied together, diazoxide alleviated the curcumin-induced apoptosis in LCur + DZ (13.51\% \pm $1.85 \%), \quad$ MCur + DZ $(27.81 \% \pm 2.24 \%)$, and $\mathrm{HCur}+\mathrm{DZ}$ $(54.22 \% \pm 2.72 \%)$. The results are shown in Figure 3. 


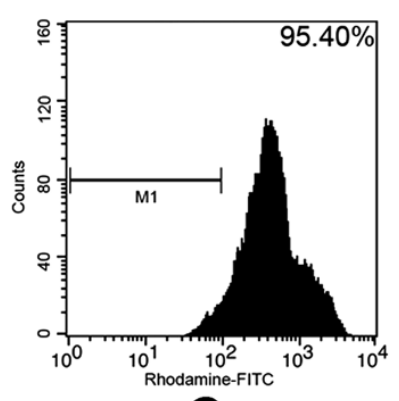

C
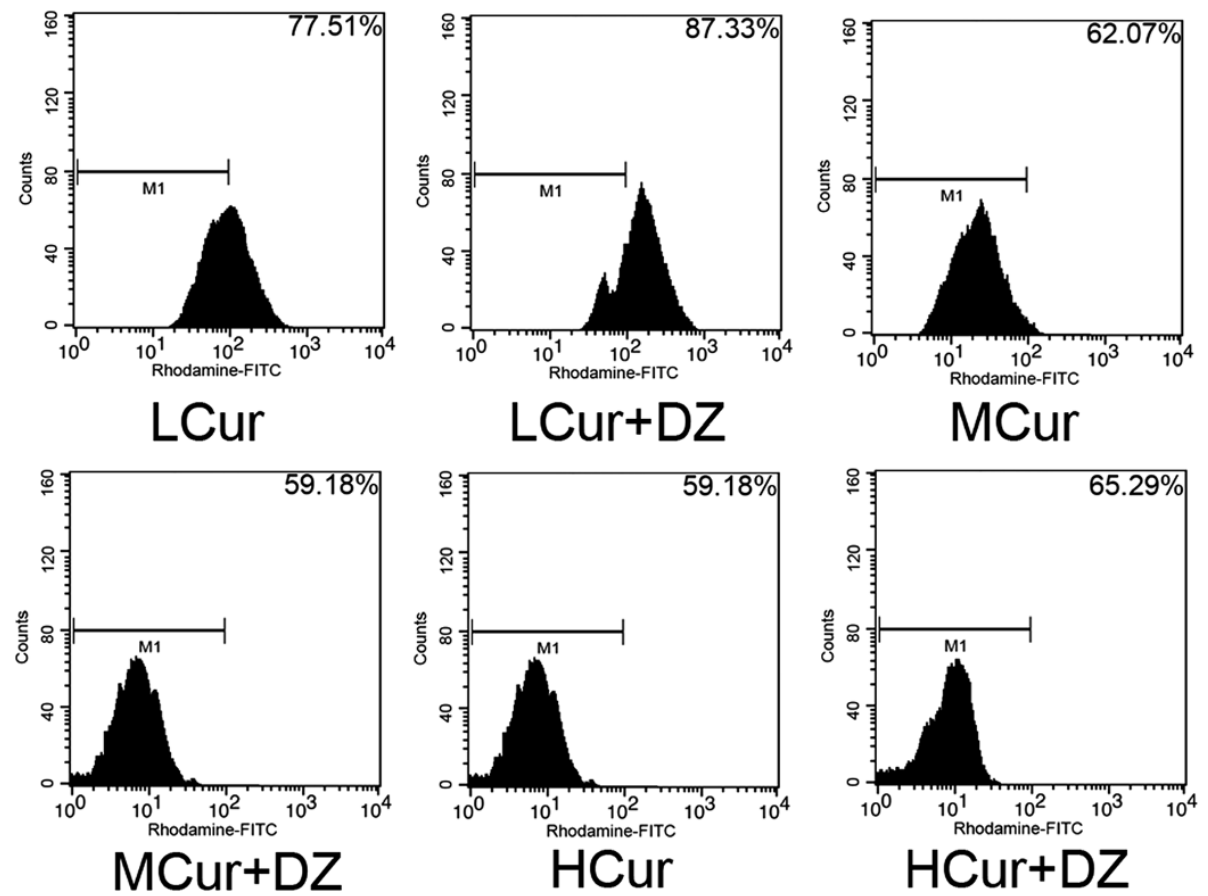

Figure 2 Effects of curcumin and its co-administration with diazoxide on mitochondrial membrane potential in cultured SGC-7901 cells. Cells were stained with rhodamine 123 and then detected by a flow cytometer. Cells with decreased MMP show less detected fluorescence from rhodamine 123. Charts of flow cytometry from top to bottom and from left to right show the detected rhodamine 123 fluorescence of $C$, LCur, LCur + DZ, MCur, MCur + DZ, HCur, and HCur + DZ. C, control; DZ, diazoxide; FITC, fluorescein isothiocyanate; HCur, high-dose curcumin; LCur, low-dose curcumin; MCur, medium-does curcumin; MMP, mitochondrial membrane potential.

Growth of xenograft tumor was reduced by curcumin but reversed by co-administration of diazoxide in vivo

At the end of 3 weeks after initiation of curcumin and diazoxide treatment, all mice were alive. After sacrifice, tumors were isolated. Compared with $C$, tumor volume was significantly reduced in Cur starting from day $7(P<0.05)$. However, tumor volume in Cur $+\mathrm{DZ}$ was significantly higher than that in Cur $(P<0.05)$. In Cur, curcumin administration showed a significant inhibitory effect on the weight of xenografts compared with $C(P<0.05)$. However, this effect was mitigated by co-administration of diazoxide $(P<0.05)$. The results are shown in Figure 4.

\section{Discussion}

We explored the involvement of $\mathrm{K}_{\mathrm{ATP}}$ in the antiproliferation effects of curcumin in gastric cancer. It was found that curcumin could inhibit the proliferation of gastric cancer cells by inducing apoptosis. Our in vitro results showed that curcumin-induced apoptosis of SGC-7901 cells by facilitating the collapse of MMP, which was believed to initiate the mitochondria-dependent apoptotic pathway. However, the co-administration of diazoxide, which is a mitoK $\mathrm{ATP}_{\text {ATP }}$ selective opener, alleviated the collapse of MMP in curcumin-incubated SGC-7901 cells. In our in vivo study, the reduction in both volume and weight of xenograft tumor by curcumin was also reversed by co-administration of diazoxide. These results indicated that curcumin could induce apoptosis of gastric cancer cells via deactivating mitoK $\mathrm{K}_{\mathrm{ATB}}$ which would expedite the collapse of MMP.

With the improvement of modern medical technology and cancer prevention, the incidence of gastric cancer 


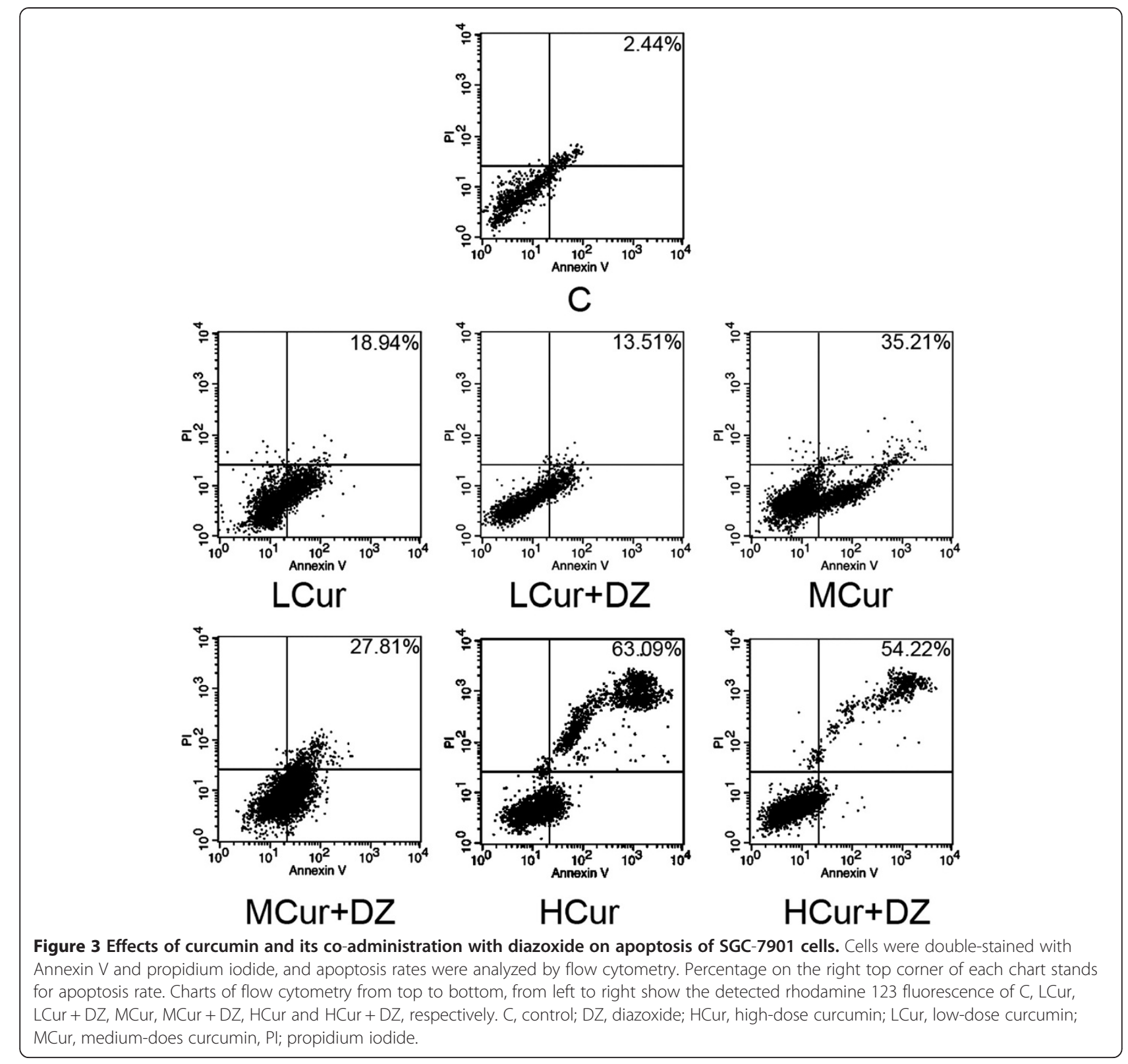

has decreased remarkably in the past few years [22]. However, globally, gastric cancer is now the second leading cause of mortality in malignant diseases [1]. The prognosis of patients with gastric cancer is poor, especially in patients with metastatic lymph nodes and low serum albumin levels, who are considered not suitable for surgical treatment [23]. Owing to the unapparent and sneaky clinical manifestations of early stage gastric cancer, patients are often only diagnosed when the cancer is at an advanced stage [24]. Thus, the current most curative therapy, surgery [25], is excluded from treatment strategies. Alternative therapies, including chemotherapy, radiotherapy, and radiochemotherapy, though effective, are none of them curative. In recent decades, several natural products originating from medicinal herbs have broadened our understanding because of their extensive biological activities [26]. Such drugs as emodin [27], curcumin [28], and matrine [29] have been demonstrated to have anti-cancer effects by inhibiting proliferation, invasion, and metastasis of multiple malignant cancers. Although many studies revealed their pharmacological mechanisms, much research is still needed.

Used as a coloring agent, spice, and flavoring, curcumin has also been widely applied since ancient times in medical systems in Eastern and Southeastern Asia as an important ingredient of medicinal formulas [30]. 
A

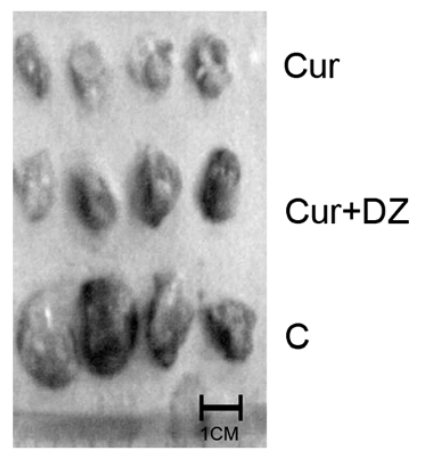

B

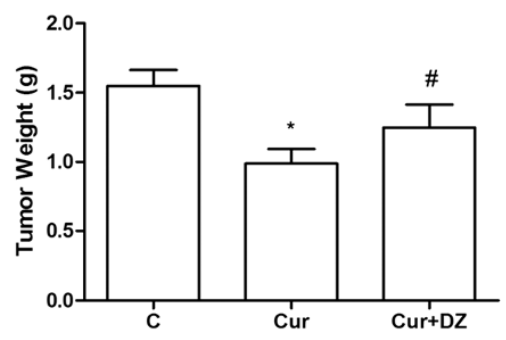

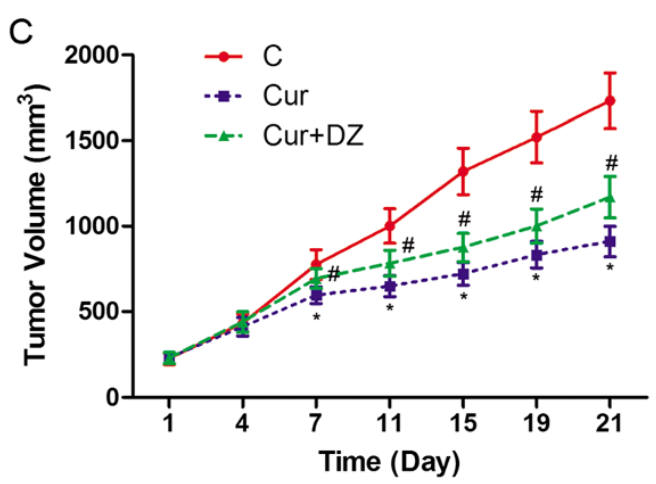

Figure 4 Effects of curcumin and its co-administration with diazoxide on growth of SGC-7901 tumor xenografts. (A) Isolated tumor xenografts from nude mice of Cur, Cur + DZ, and C at day 21. (B) Weight of isolated xenografts from nude mice of Cur, Cur + DZ, and C at day 21. (C) Tumor volume of SGC-7901 tumor xenografts in Cur (blue), Cur + DZ (green) and C (red) from day 1 to day 21. Values are represented as

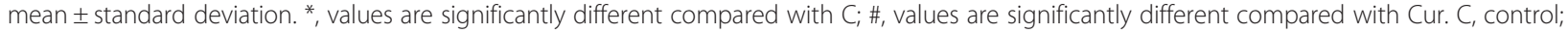
Cur, curcumin; DZ, diazoxide.

Modern medical studies found that this bioactive agent, extracted from the rhizome of a herb named Curcuma Longa Linn, exerted potent anti-cancer activity by inhibiting cell proliferation in vitro and in vivo [31]. The mechanisms involved in curcumin's proliferation inhibition were thought to be complicated: multiple pathways and molecular mediators were proved relevant. It was believed that three canonical apoptotic pathways, namely the death receptor [32], mitochondrial [33], and endoplasmic reticulum stress [34] pathways, were activated to induce apoptosis of cancer cells. Some transcriptional factor-related mechanisms, such as downregulation of TNF-induced nuclear factor $\mathrm{kB}$ mediated gene expressions [35] by curcumin were also indicated [36]. A recent report of the involvement of mitoK $\mathrm{ATP}_{\mathrm{A}}$ in regulating proliferation, invasion, and metastasis in glioma cells [37] provided new clues to the mechanisms of curcumin's anti-proliferation effects.

It was suggested that $\mathrm{K}_{\mathrm{ATP}}$ channels were distributed throughout the body, located on cell membranes and mitochondrial membranes, including malignant cells [38]. The major function of mitoK $\mathrm{K}_{\mathrm{ATP}}$ was supposed to be to adjust mitochondrial membrane functions to external stressors by opening the ion channel. Most studies concerning mitoK $\mathrm{ATP}_{\mathrm{AT}}$ have been on cardiac ischemia-reperfusion injuries [39]. Results from these studies suggest that opening of mitoK $\mathrm{K}_{\mathrm{ATP}}$ channels could protect against apoptosis [40]. At the early stage of apoptosis, the opening of mitoK $K_{\text {ATP }}$ could inhibit depolarization of mitochondrial membrane to maintain MMP [41]. Thus, the mitochondrial membrane was stabilized to prevent further apoptotic chain reaction, such as transition pore formation, cytochrome $c$ release or caspase cascade activation. Diazoxide is a widely used antihypertensive agent that acts as a selective opener of mitoK $_{\text {ATP }}$ to modulate the loss of MMP [42,43]. As a result, diazoxide could further protect cells from apoptosis.

In this study, to test the participation of mitoK $_{\mathrm{ATP}}$ in curcumin-induced apoptosis of SGC-7901 cells, diazoxide was co-administrated with curcumin to incubate SGC-7901 cells. The results of an in vitro study indicated that diazoxide co-administration alleviated the apoptosis of SGC-7901 by stabilizing MMP. The coadministration of diazoxide impaired curcumin's inhibitory effects against xenograft tumor growth. The results 
of an in vivo study consolidated the findings of the in vitro study that impaired mitoK $\mathrm{ATP}_{\mathrm{AT}}$ is one of the possible mechanisms of curcumin's anti-proliferative effects against gastric cancer.

\section{Conclusions}

We can conclude that:

1. Curcumin inhibits proliferation of gastric cancer by inducing apoptosis.

2. Impaired mitoK $\mathrm{KTP}_{\mathrm{AT}}$ opening causes MMP loss, and is involved in curcumin-induced apoptosis in gastric cancer.

\begin{abstract}
Abbreviations
C: control; Cur: curcumin; DMEM: Dulbecco's modified Eagle's medium; DZ: diazoxide; FBS: fetal bovine serum; HCur: high-dose curcumin; $\mathrm{K}_{\text {ATP }}$ : ATP-sensitive potassium channel; LCur: low-dose curcumin; MCur: medium-does curcumin; MMP: mitochondrial membrane potential; MTT: 3-(4,5-dimethylthiazol-2-yl)-2-5-diphenyltetrazolium-bromide; PBS: phosphate-buffered saline; TNF: tumor necrosis factor.
\end{abstract}

\section{Competing interests}

The authors declare that they have no competing interests.

\section{Authors' contributions}

$\mathrm{XL}$ and $\mathrm{KS}$ conducted all the experiments presented in this work. $\mathrm{HC}$ conducted the revision of the manuscript. $\mathrm{XH}$ and $\mathrm{XYZ}$ made central contributions to the conception and design of the studies, and to the analysis and interpretation of data. AS and XZ were involved in drafting the manuscript. All authors gave final approval of the version to be published. Each author has participated sufficiently in the work to take public responsibility for appropriate portions of the content.

\section{Acknowledgements}

None.

\section{Author details}

'Department of General Surgery, second affiliated hospital of Lanzhou University, Lanzhou, Gansu 730000, China. ${ }^{2}$ The Second Department of Thoracic Surgery, First Affiliated Hospital of Xi'an Jiaotong University, Xi'an, Shaanxi 710061, China. ${ }^{3}$ Department of Pathology, Lanzhou University Medical School, 199 West Donggang Road, Lanzhou, Gansu 730000, China. 4Lanzhou University, 199 West Donggang Road, Lanzhou, Gansu 730000, China.

Received: 30 June 2014 Accepted: 3 December 2014 Published: 19 December 2014

\section{References}

1. Piazuelo MB, Correa P: Gastric cancer: overview. Colomb Med (Cali) 2013, 44:192-201.

2. Choi YY, An JY, Kim Hl, Cheong JH, Hyung WJ, Noh SH: Current practice of gastric cancer treatment. Chin Med J (Engl) 2014, 127:547-553.

3. Choi Y, Choi HS, Jeon WK, Kim BI, Park DI, Cho YK, Kim HJ, Park JH, Sohn Cl: Optimal number of endoscopic biopsies in diagnosis of advanced gastric and colorectal cancer. J Korean Med Sci 2012, 27:36-39.

4. Takashima A, Shirao K, Hirashima Y, Takahari D, Okita NT, Nakajima TE, Kato K, Hamaguchi T, Yamada Y, Shimada Y: Sequential chemotherapy with methotrexate and 5-fluorouracil for chemotherapy-naive advanced gastric cancer with disseminated intravascular coagulation at initial diagnosis. J Cancer Res Clin Oncol 2010, 136:243-248.

5. Hsiao WL, Liu L: The role of traditional Chinese herbal medicines in cancer therapy - from TCM theory to mechanistic insights. Planta Med 2010, 76:1118-1131.
6. Yin SY, Wei WC, Jian FY, Yang NS: Therapeutic applications of herbal medicines for cancer patients. Evid Based Complement Alternat Med 2013, 2013:302426.

7. Zhang X, Chen LX, Ouyang L, Cheng Y, Liu B: Plant natural compounds: targeting pathways of autophagy as anti-cancer therapeutic agents. Cell Prolif 2012, 45:466-476.

8. Priyadarsini Kl: Chemical and structural features influencing the biological activity of curcumin. Curr Pharm Des 2013, 19:2093-2100.

9. Lin JK: Suppression of protein kinase $C$ and nuclear oncogene expression as possible action mechanisms of cancer chemoprevention by curcumin. Arch Pharm Res 2004, 27:683-692.

10. Yu LL, Wu JG, Dai N, Yu HG, Si JM: Curcumin reverses chemoresistance of human gastric cancer cells by downregulating the NF-KB transcription factor. Oncol Rep 2011, 26:1197-1203.

11. Lin SS, Lai KC, Hsu SC, Yang JS, Kuo CL, Lin JP, Ma YS, Wu CC, Chung JG: Curcumin inhibits the migration and invasion of human A549 lung cancer cells through the inhibition of matrix metalloproteinase- 2 and -9 and vascular endothelial growth factor (VEGF). Cancer Lett 2009, 285:127-133.

12. Hu HL, Zhang ZX, Zhao JP, Wang T, Xu YJ: Effect of opening of mitochondrial ATP-sensitive $\mathrm{K}^{+}$channel on the distribution of cytochrome $\mathrm{C}$ and on proliferation of human pulmonary arterial smooth muscle cells in hypoxia. Sheng Li Xue Bao 2006, 58:262-268.

13. Grover GJ, Garlid KD: ATP-sensitive potassium channels: a review of their cardioprotective pharmacology. J Mol Cell Cardiol 2000, 32:677-695.

14. Kurachi $Y$, Yamada M: Relationship between function and structure of ATP-sensitive $\mathrm{K}^{+}\left(\mathrm{K}_{\text {ATP }}\right.$ ) channels. Nihon Yakurigaku Zasshi 2005, 126:311-316.

15. Shen F, Wu LP, Liu WG, Lu Y, Liang HW, Xia Q: Effect of activation of mitochondrial ATP sensitive potassium channel and calcium activated potassium channel on the permeability transition of mitochondria from both normal and ischemic rat brain. Zhongguo Ying Yong Sheng Li Xue Za Zhi 2007, 23:14-18.

16. Wu L, Shen F, Lin L, Zhang X, Bruce IC, Xia Q: The neuroprotection conferred by activating the mitochondrial ATP-sensitive $\mathrm{K}^{+}$channel is mediated by inhibiting the mitochondrial permeability transition pore. Neurosci Lett 2006, 402:184-189.

17. Zhang S, Zhou F, Ding JH, Zhou XQ, Sun XL, Hu G: ATP-sensitive potassium channel opener iptakalim protects against MPP-induced astrocytic apoptosis via mitochondria and mitogen-activated protein kinase signal pathways. J Neurochem 2007, 103:569-579.

18. Ru Q, Tian X, Wu YX, Wu RH, Pi MS, Li CY: Voltage-gated and ATP-sensitive $\mathrm{K}^{+}$channels are associated with cell proliferation and tumorigenesis of human glioma. Oncol Rep 2014, 31:842-848.

19. Chen HY, Zhang X, Chen SF, Zhang YX, Liu YH, Ma LL, Wang LX: The protective effect of $17 \beta$-estradiol against hydrogen peroxide-induced apoptosis on mesenchymal stem cell. Biomed Pharmacother 2012, 66:57-63.

20. Wakiyama H, Cowan DB, Toyoda Y, Federman M, Levitsky S, McCully JD: Selective opening of mitochondrial ATP-sensitive potassium channels during surgically induced myocardial ischemia decreases necrosis and apoptosis. Eur J Cardiothorac Surg 2002, 21:424-433.

21. Lu WD, Qin Y, Yang C, Li L, Fu ZX: Effect of curcumin on human colon cancer multidrug resistance in vitro and in vivo. Clinics (Sao Paulo) 2013, 68:694-701.

22. Dassen AE, Dikken JL, Bosscha K, Wouters MW, Cats A, van de Velde CJ, Coebergh JW, Lemmens VE: Gastric cancer: decreasing incidence but stable survival in the Netherlands. Acta Oncol 2014, 53:138-142.

23. Isik A, Okan I, Firat D, Yilmaz B, Akcakaya A, Sahin M: A new prognostic strategy for gastric carcinoma: albumin level and metastatic lymph node ratio. Minerva Chir 2014, 69:147-153.

24. Thrumurthy SG, Chaudry MA, Hochhauser D, Mughal M: The diagnosis and management of gastric cancer. BMJ 2013, 347:f6367.

25. Mahar AL, Coburn NG, Singh S, Law C, Helyer LK: A systematic review of surgery for non-curative gastric cancer. Gastric Cancer 2012, 15(Suppl 1):S125-S137.

26. Arslan D, Tural D, Akar E: Herbal administration and interaction of cancer treatment. J Palliat Med 2013, 16:1466-1476.

27. Yu JQ, Bao W, Lei JC: Emodin regulates apoptotic pathway in human liver cancer cells. Phytother Res 2013, 27:251-257.

28. Bimonte S, Barbieri A, Palma G, Luciano A, Rea D, Arra C: Curcumin inhibits tumor growth and angiogenesis in an orthotopic mouse model of human pancreatic cancer. Biomed Res Int 2013, 2013:810423. 
29. Zhang P, Wang Z, Chong T, Ji Z: Matrine inhibits proliferation and induces apoptosis of the androgen-independent prostate cancer cell line PC-3. Mol Med Rep 2012, 5:783-787.

30. Kurien BT, Singh A, Matsumoto H, Scofield RH: Improving the solubility and pharmacological efficacy of curcumin by heat treatment. Assay Drug Dev Technol 2007, 5:567-576.

31. Johnson SM, Gulhati P, Arrieta I, Wang X, Uchida T, Gao T, Evers BM: Curcumin inhibits proliferation of colorectal carcinoma by modulating Akt/mTOR signaling. Anticancer Res 2009, 29:3185-3190.

32. Zhu S, Li T, Tan J, Yan X, Zhang D, Zheng C, Chen Y, Xiang Z, Cui H: Bax is essential for death receptor-mediated apoptosis in human colon cance cells. Cancer Biother Radiopharm 2012, 27:577-581.

33. Kim KY, Yu SN, Lee SY, Chun SS, Choi YL, Park YM, Song CS, Chatterjee B, Ahn SC: Salinomycin-induced apoptosis of human prostate cancer cells due to accumulated reactive oxygen species and mitochondrial membrane depolarization. Biochem Biophys Res Commun 2011, 413:80-86.

34. Chiu SC, Chen SP, Huang SY, Wang MJ, Lin SZ, Harn HJ, Pang CY: Induction of apoptosis coupled to endoplasmic reticulum stress in human prostate cancer cells by $n$-butylidenephthalide. PLoS One 2012, 7:e33742.

35. Bours V, Bentires-Alj M, Hellin AC, Viatour P, Robe P, Delhalle S, Benoit V, Merville MP: Nuclear factor-kappa B, cancer, and apoptosis. Biochem Pharmacol 2000, 60:1085-1089.

36. Zong $\mathrm{H}$, Wang F, Fan QX, Wang LX: Curcumin inhibits metastatic progression of breast cancer cell through suppression of urokinase-type plasminogen activator by NF-kB signaling pathways. Mol Biol Rep 2012, 39:4803-4808.

37. Paino T, Gangoso E, Medina JM, Tabernero A: Inhibition of ATP-sensitive potassium channels increases HSV-tk/GCV bystander effect in U373 human glioma cells by enhancing gap junctional intercellular communication. Neuropharmacology 2010, 59:480-491.

38. Bodenstine TM, Vaidya KS, Ismail A, Beck BH, Diers AR, Edmonds MD, Kirsammer GT, Landar A, Welch DR: Subsets of ATP-sensitive potassium channel $\left(K_{\text {ATP }}\right)$ inhibitors increase gap junctional intercellular communication in metastatic cancer cell lines independent of SUR expression. FEBS Lett 2012, 586:27-31.

39. Khimenko PL, Moore TM, Taylor AE: ATP-sensitive $\mathrm{K}^{+}$channels are not involved in ischemia-reperfusion lung endothelial injury. J Appl Physiol (1985) 1995, 79:554-559.

40. Wang L, Zhu QL, Wang GZ, Deng TZ, Chen R, Liu MH, Wang SW: The protective roles of mitochondrial ATP-sensitive potassium channels during hypoxia-ischemia-reperfusion in brain. Neurosci Lett 2011, 491:63-67.

41. Garg V, Hu K: Protein kinase C isoform-dependent modulation of ATP-sensitive $\mathrm{K}^{+}$channels in mitochondrial inner membrane. Am J Physiol Heart Circ Physiol 2007, 293:H322-H332.

42. Jia D: The protective effect of mitochondrial ATP-sensitive $\mathrm{K}^{+}$channel opener, nicorandil, combined with $\mathrm{Na}^{+} / \mathrm{Ca}^{2+}$ exchange blocker KB-R7943 on myocardial ischemia-reperfusion injury in rat. Cell Biochem Biophys 2011, 60:219-224.

43. Pringle MJ, Sanadi DR: Effects of $\mathrm{Cd}^{2+}$ on ATP-driven membrane potential in beef heart mitochondrial $\mathrm{H}^{+}$-ATPase: a study using the voltage-sensitive probe oxonol VI. Membr Biochem 1984, 5:225-241.

doi:10.1186/1477-7819-12-389

Cite this article as: Liu et al:: Curcumin inhibits proliferation of gastric cancer cells by impairing ATP-sensitive potassium

channel opening. World Journal of Surgical Oncology 2014 12:389.

\section{Submit your next manuscript to BioMed Central and take full advantage of:}

- Convenient online submission

- Thorough peer review

- No space constraints or color figure charges

- Immediate publication on acceptance

- Inclusion in PubMed, CAS, Scopus and Google Scholar

- Research which is freely available for redistribution 